\title{
LIBERDADE POSITIVA E NEGATIVA NO LIBERALISMO POLÍTICO DE RAWLS
}

\author{
Cesar Augusto Ramos \\ Pontifícia Universidade Católica do Paraná
}

\begin{abstract}
This paper aims to present an analysis of Rawls on freedom, linked to the conception of person, as a central point of his political liberalism. This analysis includes both the negative freedom and the positive in the I. Berlin classification, in his essay Two concepts of liberty. The appropriation of negative freedom by Rawls, which is expressed in the basic freedoms ("primary goods"), is present with priority in the first principle of justice. The model conception of person constructs by Rawls implies to take over the idea of freedom as something that conceptually belongs to the person in regard to its autonomy, therefore, accomplishing the requirement of a positive concept of freedom. As a result of this analysis, the recognition of freedom and equality of persons and their status as moral subjects plays a key role that each person ascribes to himself as a free and moral subject, and considers the other as well as having equal capacity.
\end{abstract}

KEYWORDS: freedom, person, political liberalism.

RESUMO: Este trabalho pretende apresentar a análise de Rawls sobre a liberdade, vinculada à concepção de pessoa, como um ponto central do seu liberalismo político. Essa análise contempla tanto a liberdade negativa como a positiva na classificação de I. Berlin, em seu ensaio Dois conceitos de liberdade. A apropriação da liberdade negativa por Rawls, a qual se exprime nas liberdades básicas ("bens primários") está, prioritariamente, presente no primeiro princípio de justiça. A concepção modelo de pessoa que Rawls constrói implica assumir a ideia de liberdade como algo que conceitualmente pertence à pessoa no que diz respeito à sua autonomia, realizando, assim, a exigência conceitual de sentido positivo de liberdade. Como resultado desta análise, o reconhecimento da liberdade e da igualdade das pessoas e da sua condição como sujeitos morais desempenha um papel fundamental no valor que cada pessoa atribui a si como sujeito moral livre, e que considera o outro também como possuidor de igual capacidade.

PALAVRAS-CHAVE: liberdade, pessoa, liberalismo político. 
A sociedade é, para Rawls, uma associação mais ou menos autossuficiente que estabelece regras de cooperação e busca promover o bem daqueles que dela fazem parte segundo princípios de justiça, e de acordo com uma determinada concepção de pessoa. Para que essa sociedade possa realizar os seus objetivos, as pessoas devem possuir atributos que permitem a convivência social harmoniosa e justa, apesar dos conflitos e das diferentes concepções de bem e de vida que cada um ostenta. Além das condições gerais, relacionadas a determinadas capacidades cognitivas e morais, que asseguram a compreensão e a realização dos termos de um acordo razoável entre as pessoas para a vida social, a liberdade, a igualdade e a cooperação são atributos da pessoa (e do cidadão) que melhor cumprem os objetivos para a realização de uma sociedade bem-ordenada, regulada por princípios de justiça. ${ }^{1}$

Pluralista e estável, essa sociedade permite a criação de formas diversas e, muitas vezes, conflitantes de vida das pessoas. Ela deve ser suficientemente estável para propiciar a proteção para os seus membros, sobretudo, no que diz respeito às liberdades individuais, assegurando, assim, o pluralismo nas concepções de bem e o pleno desenvolvimento da autonomia de indivíduos iguais e cooperativos. Não há nenhuma forma de vida, individual ou coletiva que seja preferível em detrimento a qualquer outra. A pluralidade das concepções de bem e a existência de diversas doutrinas morais, filosóficas e religiosas, atestam a liberdade fundamental de cada indivíduo. Por conseguinte, um aspecto fundamental na formulação do liberalismo político é o reconhecimento teórico e histórico do pluralismo nas sociedades democráticas modernas, o qual tem por pressuposto a própria noção, também democrática, de tolerância.

Para uma sociedade assim concebida - desde a sua origem segundo princípios de justiça normativos do contrato social, até a sua consolidação institucional - a liberdade constitui um ponto central na teoria de Rawls da

\footnotetext{
1 Para Rawls, a ideia de uma sociedade bem-ordenada é aquela regulada por uma concepção pública de justiça. Ela é representada por três aspectos: "1) que é uma sociedade em que todos os cidadãos aceitam, e reconhecem perante os outros que aceitam, os mesmos princípios de justiça; 2) que se reconhece publicamente ou com boas razões se acredita que sua estrutura básica, suas principais instituições políticas e sociais e a maneira como se articulam num sistema de cooperação, satisfaz esses princípios; e 3) que os cidadãos têm normalmente um senso de justiça efetivo, ou seja, um senso que lhes permite compreender e aplicar os princípios de justiça, e, de forma geral, agir em função deles quando as circunstâncias assim 0 exigem. A unidade social assim entendida é a concepção mais desejável de unidade de que dispomos: é o limite do melhor possível." (RAWLS, J. Justiça como equidade. Uma reformulação. Trad. Claudina Berliner, São Paulo: Martins Fontes, 2003, p. 283/4).
} 
justiça como equidade, e acompanha a sua evolução no contexto do liberalismo político. Segundo o autor, uma concepção liberal da justiça deve ter os seguintes (três) elementos principais:

primeiro, a especificação de certas liberdades, de oportunidades e de direitos básicos (como aqueles que são bem conhecidos nos regimes democráticos constitucionais); segundo, a determinação de uma prioridade particular atribuída a essas liberdades, a essas oportunidades e a esses direitos, examinando, muito especialmente, as reivindicações relativas ao bem geral e aos valores do perfecionismo; terceiro, medidas que assegurem a cada cidadão os meios adequados e polivalentes que permitam o uso eficaz de suas liberdades e de suas oportunidades básicas. ${ }^{2}$

Um dos objetivos de Uma teoria da justiça consiste em fornecer uma análise convincente das liberdades básicas e consignar a sua prioridade em princípios de justiça. ${ }^{3}$ A originalidade de Rawls está em dizer que esses princípios regem a estrutura de base da sociedade e são válidos se eles resultarem de um acordo original. Eles não contrariam a concepção filosófica

\footnotetext{
2 RAWLS, J. Justiça e democracia. Trad. Irene A. Paternot, São Paulo: Martins Fontes, 2000 p. 277. Na nota correspondente a essa citação, Rawls acrescenta outras condições para formar uma ideia mais completa de uma concepção liberal de justiça: "1) a autoridade política deve respeitar o Estado de direito e uma concepção do bem comum que compreende o bem de cada cidadão; 2) a liberdade de consciência ou de pensamento deve ser garantida, e isso deve estender-se à liberdade de seguir a sua própria concepção do bem, ficando entendido que esta não deve violar os princípios de justiça; 3 ) direitos políticos iguais devem ser garantidos, assim como a liberdade de imprensa e de associação, 0 direito de constituir partidos, que pressupõe por outro lado a eventualidade de uma oposição leal; 4) a igualdade das oportunidades e a livre escolha de um trabalho devem ser mantidas na perspectiva de oportunidades variadas; e 5) todos os cidadãos devem ter a garantia de uma distribuição equitativa dos meios materiais, de modo que eles sejam suficientemente independentes e possam tirar proveito da igualdade dos seus direitos básicos, das liberdades e das oportunidades equitativas." (idem, p. 277).

3 Os princípios de justiça têm a seguinte formulação: "a. Cada pessoa tem igual direito a um esquema plenamente adequado de iguais direitos e liberdades básicos, sendo cada esquema compatível com 0 mesmo esquema para todos; e, nesse esquema, as iguais liberdades políticas, e apenas estas, devem ter o seu justo valor garantido. b. As desigualdades econômicas e sociais devem satisfazer duas condições: primeiro têm de estar ligadas a posições e cargos aos quais todas as pessoas têm acesso de acordo com a igualdade equitativa de oportunidades; e segundo, têm de ser para 0 maior benefício possível dos membros menos favorecidos da sociedade." RAWLS, J. Liberalismo político. Trad. João S. Nunes, Lisboa: Editorial Presença, 1996. Esses princípios de justiça foram citados segundo a versão modificada que Rawls Ihes dá no Liberalismo político (1993). A mudança em relação à versão original exposta na Teoria da justiça envolve a reelaboração de algumas expressões e a introdução de alguns termos. Mas a estrutura conceitual e a ordem de prioridade dos princípios permanecem as mesmas.
} 
de que as pessoas são livres e racionais na busca de seus interesses e que podem, assim, ser colocados numa "posição original", determinando as formas fundamentais da associação e servindo de regra para todos os acordos ulteriores. Trata-se, portanto, de uma perspectiva nitidamente alinhada com o pensamento político liberal de ênfase aos direitos e às liberdades individuais, atributos que devem ser tomados como realidades fundacionais e primárias, sobre as quais são erigidas as instituições sociais e políticas, e cuja legitimidade nasce do contrato social. Tais liberdades estão prioritariamente presentes no primeiro princípio de justiça.

Ainda que reconhecendo a liberdade como ponto central da sua teoria, a intenção de Rawls não está voltada para a discussão filosófica sobre o sentido conceitual do que ela é em si mesma: "não se atribui prioridade alguma à liberdade como tal; se assim fosse, o exercício de uma coisa chamada 'liberdade' teria um valor preeminente e seria a meta principal, se não a única, da justiça social e política." ${ }^{4}$ A estratégia do filósofo consiste em constatar a realidade das liberdades básicas que se consolidaram ao longo da história do pensamento democrático, e que se tornaram garantias constitucionais no ordenamento jurídico dos Estados modernos. O registro histórico do fato da liberdade revela um significado conceitual análogo à concepção de cunho liberal da liberdade negativa - na classificação sugerida por I. Berlin no seu conhecido ensaio Dois conceitos de liberdade ${ }^{5}$, e que se manifesta na concepção rawlsiana de liberdade.

\footnotetext{
${ }^{4}$ RAWLS, J. Justiça e democracia, op. cit., p. 145.

${ }^{5} \mathrm{~A}$ discussão liberal sobre a liberdade foi equacionada de modo exemplar por I. Berlin no ensaio Dois Conceitos de Liberdade. Segundo esse autor, a liberdade possui dois sentidos. No sentido negativo, ela é compreendida como ausência de impedimentos ou de obstáculos (por isso ela é chamada de negativa) para o exercício de ações que os indivíduos deliberadamente desejam realizar. Este conceito de liberdade segue a intuição hobbesiana de que o indivíduo é livre quando está desimpedido de exercer 0 seu poder e as suas capacidades para alcançar os fins que deseja, realizando, assim, uma ação que tinha intenção de fazer sem impedimento externo. De um modo geral, observa Berlin, "diz-se que sou livre na medida em que nenhum indivíduo ou conjunto de indivíduos interfere com a minha atividade. Se eu for impedido por outros de fazer o que poderia fazer se assim não fosse, nessa medida eu não sou livre; e se essa área for restringida por outros homens para lá de um determinado mínimo, poder-se-á dizer que sou coagido ou, até, oprimido." (BERLIN, I. Dois conceitos de liberdade. In: HARDY, H. et al. (ed.) A Busca do ideal. Uma antologia de ensaios. Trad. Teresa Curvelo, Lisboa: Editorial Bizâncio, 1998, p. 246). Esta acepção de liberdade visa responder à pergunta: "qual a área dentro da qual ao sujeito - um indivíduo ou um grupo de indivíduos - é ou deve ser permitido fazer ou ser o que é capaz de fazer ou ser, sem a interferência de outras pessoas?" (idem, p. 246). No sentido positivo, a liberdade é vista como a capacidade de autodeterminação do indivíduo mediante a autonomia da vontade. Ela é positiva porque indica a presença de algo (a vontade autônoma, a autodeterminação e a autorealização) para que o indivíduo possa seguir seus desejos ou suas preferências racionais sobre como
} 
O conceito (liberal) de liberdade negativa, na distinção proposta por Berlin, está presente em Rawls, o qual se traduz nas liberdades básicas ("bens primários”), declaradas no primeiro princípio de justiça. Para o liberalismo político, uma sociedade aberta e democrática, na qual vários modos de vida competem, a concepção de liberdade é de extrema importância, e deve ser compreendida na referência a três elementos: os agentes livres, as restrições ou limitações das quais eles estão livres, e aquilo para o qual eles são livres para fazer ou não fazer. "A descrição geral de uma liberdade, então, assume a seguinte forma: esta ou aquela pessoa (ou pessoas) está (ou não está) livre desta ou daquela restrição (ou conjunto de restrições) para fazer (ou não fazer) isto ou aquilo."6

A liberdade negativa está presente nesta descrição na ênfase ao elemento da ausência de impedimentos para que a ação de alguém possa fazer (ou não fazer), tornar-se (ou não tornar-se) isto ou aquilo. Ela é definida por "direitos e deveres institucionais que dão aos cidadãos o direito de agir como desejarem e que impedem os outros de interferir." " Trata-se das liberdades básicas que configuram uma lista, a saber: "a liberdade de pensamento e a liberdade de consciência, as liberdades políticas e a liberdade de associação, bem como as liberdades incluídas na noção de liberdade e de integridade da pessoa e, finalmente, os direitos e liberdades protegidos pelo Estado de direito." São liberdades que, definidas por direitos e deveres institucionais, constituem um conjunto articulado de meios e possibilidades legalmente protegidos que permitem aos cidadãos o direito de agir como desejam, resguardando-os de interferências indevidas dos outros ou do Estado.

O filósofo norte-americano segue, assim, a tradição liberal e a sua compreensão de liberdade é, decididamente, negativa, retratada por um conjunto de princípios formais atribuídos a cada cidadão para lhes assegurar

ele deve agir e viver, revelando o desejo de ser senhor de si mesmo e da sua atividade. A liberdade positiva, por sua vez, visa responder à questão: "o quê ou quem constitui a origem do controle ou da interferência capaz de determinar que alguém faça ou seja isto em vez daquilo?" (idem, p. 246). De inspiração rousseauísta-kantiana, este conceito opera com a ideia de autonomia da vontade, mediante a qual o sujeito se autodetermina como livre na medida em que ele controla a sua vida, é senhor das suas ações e desejos, sujeito das suas escolhas e do modo de vida que ele quer levar, não está submetido à vontade de outrem, permitindo, assim, o autogoverno na esfera privada, e coletivo na esfera pública.

${ }^{6}$ RAWLS, J. Uma teoria da justiça. Trad. Almiro Piseta e Lenita M.R. Esteves. São Paulo: Martins Fontes, 1997, p. 219.

${ }^{7}$ RAWLS, J. Justiça e democracia, op. cit., p. 176.

${ }^{8}$ Idem, p. 145. 
o pleno exercício das suas liberdades mediante proteção institucional. "As liberdades básicas são definidas por direitos e deveres institucionais que dão aos cidadãos o direito de agir como desejarem e que impedem os outros de interferir. As liberdades básicas constituem um conjunto articulado de meios e possibilidades legalmente protegido" " Nesse sentido, a liberdade é retratada em uma certa estrutura de instituições e em normas públicas que definem direitos e deveres que permitem às pessoas fazerem o que elas desejam fazer quando estão livres de restrições e quando as suas ações estão protegidas contra a interferência de outras pessoas. A liberdade significa, portanto, que "não apenas deve ser permissível que os indivíduos façam ou não façam uma determinada coisa, mas também o governo e as outras pessoas devem ter a obrigação legal de não criar obstáculos."10

A liberdade negativa, mediante a proteção jurídica das liberdades constitucionais das sociedades liberais democráticas, se reporta a fatores externos na interação entre os indivíduos, tornando-se mais fácil avaliar aquilo que cria impedimentos de acordo com princípios normativos legais que garantem o livre curso das ações, em consonância com a tese de que o sentido da liberdade individual deve ser considerado como esfera de independência pessoal e um meio para assegurar a liberdade de escolha. Esta forma de liberdade tem prioridade, pois, a "liberdade básica só pode ser limitada ou negada a fim de salvaguardar uma ou várias das outras liberdades básicas, e jamais [...] em nome do bem público ou de valores perfeccionistas." 11

A razão fundamental por essa preferência está ligada à defesa dos princípios liberais do pluralismo ético e político, consequência inevitável da condição humana definida por escolhas marcadas pelo conflito, amparando a diversidade de concepções e diferentes estilos de comportamento e formas de vida. Berlin entende que apenas mediante a força impeditiva da liberdade negativa é que se pode criticar o monismo ético na busca da ordem e da harmonia, porque se assegura a capacidade de escolha como traço essencial dos seres humanos. A consequência da defesa dessa capacidade é a sustentação de uma sociedade pluralista e competitiva na realização de

\footnotetext{
9 Idem, p. 179.

${ }^{10}$ RAWLS, J. Uma teoria da justiça, op. cit., p. 219.

11 Idem, p. 150.
} 
valores, muitas vezes, incomensuráveis entre si e irredutíveis a qualquer forma de monismo ético, político ou religioso.

O pluralismo, com a dose de liberdade 'negativa' que acarreta, pareceme um ideal mais verdadeiro e mais humano do que os objetivos dos que procuram nas grandes estruturas disciplinadoras a autoritárias o ideal do auto- domínio 'positivo' de classes, de povos ou de toda a humanidade. Mais verdadeiro porque, pelo menos, reconhece o fato de os objetivos humanos serem múltiplos, nem todos comensuráveis, e em perpétua emulação entre si. $^{12}$

Nesse ponto, Rawls concorda com Berlin na tese de que a melhor forma de proteger o pluralismo consiste na defesa da liberdade negativa, e que as duas formas de liberdade não são meramente distintas, mas podem revelar ideais políticos diferentes. Mediante essa liberdade (negativa), o pluralismo é resguardado como elemento essencial para a sustentação de uma sociedade democrática que exclui o monismo do bem, ou o exclusivismo de doutrinas morais perfeccionistas. $\mathrm{O}$ modo mais adequado para a manifestação do pluralismo razoável está em assegurar, mediante a lei, o exercício dessa forma de liberdade, uma vez que ela representa o recurso mais eficaz à preservação da diversidade das concepções de bem. Assim, nenhuma doutrina filosófica, religiosa ou moral particular pode se impor de forma hegemônica nas sociedades modernas, prevalecendo a coexistência do pluralismo de ideias e de valores na concepção de bem das pessoas numa sociedade liberal. Na teoria da justiça como equidade, "a existência de divergências de opinião profundas e irreconciliáveis, e que dizem respeito às questões capitais para o ser humano, é considerada como um elemento permanente da condição humana e deve ser tomada em consideração quando se constrói uma concepção da justiça"13

Além do seu entendimento jurídico como o conjunto de princípios formais das chamadas de liberdades básicas que garantem o livre exercício das ações de ingerências indevidas da chamada liberdade negativa, Rawls não se contenta em estabelecer uma lista dos direitos e das liberdades básicas inscritas nas Constituições dos Estados modernos. Pretende, também, analisar a questão da liberdade sob o aspecto positivo, compatível com a tese

${ }^{12}$ BERLIN, I. Dois conceitos de liberdade, op. cit. p. 294.
${ }^{13}$ RAWLS, J. Justiça e democracia, op. cit., p 90,91. 
do pluralismo na defesa da liberdade negativa como forma de preservar a livre escolha das concepções do bem pelos indivíduos.

O alinhamento ao sentido da tradição liberal da assim chamada liberdade negativa - prioritariamente presente no primeiro princípio de justiça - não exclui a presença da liberdade próxima ao significado da liberdade positiva, na medida em que ela pode, também, ser vista como atributo da pessoa - parceiro que vai escolher princípios de justiça, dentre os quais o mais importante é, justamente, a liberdade - e do cidadão de uma sociedade bem-ordenada. A caracterização dos bens primários ou das liberdades de base não se limita à sua consideração de bens jurídicos e constitucionais, mas está aderente ao sentido filosófico normativo da ideia de pessoa, constituindo elemento essencial para a elaboração de sua teoria da justiça como equidade. ${ }^{14}$

A escolha dos princípios de justiça não é tarefa fácil em razão da diversidade das alternativas, e diante da liberdade de arbítrio das pessoas. A estratégia de Rawls para chegar a eles consiste em: 1) definir uma determinada concepção de pessoa como partícipe na relação contratual, a qual se determina segundo uma concepção de sujeito - definido como pessoa autônoma - e que vai dar o consentimento a esses princípios; 2) encontrar uma posição inicial (que ele chama de "posição original") na qual é possível a escolha racional dos princípios; e 3) se esses princípios forem aceitos consensualmente, mediante o procedimento contratualista, eles passam a regular a estrutura de base da sociedade. ${ }^{15}$

São princípios que pessoas livres e racionais, preocupadas em promover seus próprios interesses, aceitariam numa posição inicial de igualdade como definidores dos termos fundamentais de sua associação. Esses princípios devem regular todos os acordos subsequentes; especificam os tipos de cooperação social que se podem assumir e as formas de governo que

\footnotetext{
${ }^{14}$ No Prefácio à tradução francesa de Uma teoria da justiça, Rawls reconhece a necessidade de fazer algumas reformulações em relação ao seu texto original de 1971. Por exemplo, a análise dos chamados "bens primários" passam a ser definidos "pelas necessidades das pessoas em razão do seu estatuto de cidadãos livres e iguais", e assegurados aos indivíduos na condição de pessoas e não por causa das preferências e dos desejos de cada um. (RAWLS, J. Théorie de la justice, trad. C. Audard. Paris, Seuil, 1987, p. 11).

${ }^{15}$ A alternativa seguida por Rawls na escolha dos princípios de justiça rejeita a solução utilitarista e perfeccionista. Também não propõe um ponto de vista de um sujeito (racional) que tem amplo conhecimento da situação e faz a melhor escolha diante das alternativas que tem diante de si. De igual modo, rejeita a ideia de sujeitos dotados de princípios morais substantivos ou de evidências de verdade que orientam a melhor escolha.
} 
se podem estabelecer. A essa maneira de considerar os princípios de justiça eu chamarei de justiça como equidade. ${ }^{16}$

No que se refere à concepção de pessoa, constitui tarefa fundamental definir quem são os indivíduos (os sujeitos contratantes) que vão escolher os princípios de justiça e em que condições devem fazê-lo. Um dos pilares da teoria da justiça de Rawls consiste em elaborar uma concepção de pessoa como um elemento conceitual basilar para a elaboração da sua teoria. "Sem as ideias da sociedade e da pessoa as concepções do justo e do bem são impertinentes. São ideias tão básicas como as de juízo e de inferência e como os princípios de razão prática." ${ }^{17}$ Do ponto de vista da sua construção, o conceito de pessoa é elaborada a partir de uma tríplice perspectiva: a de uma pessoa fictícia que habita uma posição hipotética para escolher princípios de justiça; a de uma pessoa idealmente concebida como cidadão de uma sociedade bem-ordenada que será regulada pelos princípios de justiça; e a perspectiva de quem elabora essa concepção a partir de uma situação concreta submetida a uma depuração conceitual, mediante o processo do "equilíbrio refletido" (reflective equilibrium). Apenas esse último aspecto é propriamente real. Os outros dois são abstratos segundo a metodologia da concepção modelo, configurando uma idealização de certas ideias que estão latentes na nossa cultura democrática. "A concepção de pessoa é, em si, normativa e política e não metafísica ou psicológica."18

Ainda que o conhecimento histórico das liberdades individuais influencie o conteúdo dos princípios de justiça como escolhas possíveis pelos parceiros, o procedimento decisivo para a constituição das liberdades básicas (liberdade negativa), bem como a razão principal para que essas liberdades sejam consignadas no primeiro princípio de justiça de forma prioritária, está vinculado à concepção normativa de pessoa.

A segunda maneira de elaborar a lista é examinar quais são as liberdades que constituem condições sociais essenciais que permitem o desenvolvimento adequado e o pleno exercício das duas faculdades da personalidade moral ao longo de uma vida completa. Dessa maneira, as liberdades básicas ficam ligadas à concepção da pessoa utilizada na teoria da justiça como equidade ${ }^{19}$.

\footnotetext{
${ }^{16}$ RAWLS, J. Uma teoria da justiça, op. cit., p. 12.

${ }^{17}$ RAWLS, J. Justiça e democracia, op. cit., p. 122.

${ }^{18}$ RAWLS, J. Justiça como equidade. Uma reformulação, op. cit., p. 26.

${ }^{19}$ RAWLS, J. Justiça e democracia, op. cit., p. 147.
} 
As partes devem ser consideradas como "representantes de cidadãos livres e iguais." Não são pessoas reais de uma sociedade, mas "agentes racionais da construção", "pessoas artificiais que idealizamos para que habitem uma posição original, como um recurso de representação.” Esse recurso permite descrever a pessoa como o resultado de um artifício: um ponto de vista que o homem adota para observar o seu papel e a maneira que ele pode se representar numa possível posição original. ${ }^{20}$

Uma concepção de justiça que melhor convém à sociedade é aquela que seria adotada em uma situação hipotética entre indivíduos concebidos como pessoas livres e morais, e que estão dispostos em condições apropriadas e equitativas (fair) não permitindo que alguns deles obtenham vantagens na negociação. A ideia da concepção original associada ao véu de ignorância constitui, assim, o recurso mais razoável para se estabelecer os termos justos da cooperação social numa sociedade bem-ordenada regida por princípios de justiça previamente acordados.

Portanto, junto com a concepção de pessoa, a ideia da posição original representa uma necessidade metodológica, a qual retrata não propriamente um ponto de partida axiomático a partir do qual se deduz determinados princípios, mas uma estratégia para selecionar aqueles que são os mais adequados segundo uma determinada concepção de pessoa. Trata-se de um recurso hipotético que guarda certa semelhança com o método heurístico da hipótese do estado de natureza das teorias clássicas do direito natural. ${ }^{21} \mathrm{Na}$ posição original, os princípios de justiça são escolhidos sob um "véu de ignorância" que colocam os parceiros, representantes dos cidadãos da sociedade, em situação de igualdade. Eles ignoram o seu lugar nesta mesma sociedade, sua posição e estatuto social, o lugar que será reservado a cada um na repartição dos dons e capacidades. Enfim, o contexto social e particular de cada pessoa é ignorado, abstraindo-se o aspecto psicológico e histórico, de tal forma que a heteronomia das circunstâncias particulares e sociais não afetem o marco inicial.

\footnotetext{
20 No Liberalismo político, Rawls relata que muitas das críticas à sua Teoria da justiça - a acusação de que ela se apoia sobre uma concepção abstrata de pessoa e opera com uma ideia individualista, não social, da natureza humana — decorrem do fato de não se ver "na ideia da posição original um método de representação." A retomada mais consistente e elaborada do conceito de representação como recurso metodológico para caracterizar a situação das partes na posição original, constitui um aspecto central para rebater as críticas e precisar a noção de pessoa.

${ }^{21}$ RAWLS, J. Justiça e democracia, op. cit., p. 13.
} 
O tratamento que Rawls dá à concepção modelo de pessoa consiste em compreendê-la como um dispositivo de representação (device of representation). $\mathrm{Na}$ posição original, a pessoa é vista pelo artifício da representação, elaborada pelo método da abstração, o qual, além de ostentar um valor prático para dirimir o conflito, tem também uma função heurística para encontrar uma concepção política da justiça como equidade. Numa importante passagem metodológica, o autor diz que o trabalho de abstração não é gratuito: não se trata de abstrair por abstrair. Pelo contrário,

é uma forma de prosseguir a discussão pública quando os entendimentos partilhados de menor generalidade soçobram. Devemos estar preparados para descobrir que, quanto mais profundo é o conflito, maior é o nível de abstração a que devemos ascender para obter uma perspectiva clara e descomprometida das suas raízes. Visto que os conflitos sobre a natureza da tolerância e sobre a base da cooperação para assegurar a igualdade têm persistido na tradição democrática, podemos supor que são profundos. Assim, para ligar esses conflitos com as coisas conhecidas e básicas, olhamos para as ideias fundamentais implícitas na cultura política pública e procuramos descobrir como é que os próprios cidadãos podem, após a reflexão devida, querer conceber a sua sociedade como um sistema equitativo de cooperação ao longo do tempo. Nesse contexto, é essencial formular concepções idealizadas da sociedade e da pessoa, portanto, necessariamente abstratas, associadas àquelas ideias fundamentais, para encontrar uma concepção política razoável da justiça. ${ }^{22}$

Essa metodologia possui uma dupla configuração relativa ao alcance e à finalidade. No que diz respeito ao alcance, a construção da concepção modelo pretende definir no âmbito da abstração teórica uma concepção de pessoa que pode, normativamente, ser atribuída a todos - em razão do princípio da isonomia - caso fosse pensada na hipótese da construção de uma posição inicial (original). No que se refere à finalidade, uma vez constituída a teoria a partir dos dois princípios de justiça que irão balizar a função social das instituições

${ }^{22}$ RAWLS, J. Liberalismo político, op. cit. p. 69. 
na sociedade bem ordenada segundo critérios objetivos de justiça e não segundo conveniências utilitaristas, as pessoas têm por objetivo elaborar uma lista de bens sociais primários que devem ser compatíveis com o status normativo da pessoa. Para tanto, a concepção modelo de pessoa deve possuir duas capacidades: ter um senso de justiça, isto é, de agir segundo os princípios de justiça nos termos equitativos da cooperação social, e ter autonomia para formar, revisar e seguir racionalmente uma concepção do bem.

$\mathrm{Na}$ condição de parceiros na posição original, as pessoas são morais, livres e iguais, ainda que submetidas às restrições do véu de ignorância. Elas representam apenas o racional, enquanto representantes racionalmente autônomos das pessoas na sociedade. São livres porque elas "consideram que é de seu interesse superior submeter à regra da razão, isto é, à regra de princípios racionais e razoáveis que exprimem a sua autonomia, todos os seus outros interesses, até os mais fundamentais." 23 São, portanto, considerados como "agentes racionalmente autônomos" e, nessa medida, são livres, isto é, têm a "capacidade de formular reivindicações de maneira autônoma." ${ }^{24}$ A liberdade, nesse sentido, é vista pelo lado de que é racional compreender escolhas que derivam exclusivamente da autonomia das pessoas, e é atribuída aos parceiros (pessoas representantes) na "posição original" para formular reivindicações que desejam realizar.

A concepção modelo de pessoa que o autor constrói implica assumir a ideia de liberdade como algo que pertence à pessoa no que diz respeito à sua autonomia, contemplando a exigência conceitual de sentido positivo de liberdade. Se a liberdade, na perspectiva da autonomia da vontade, é um atributo da pessoa que deve ser imputado a todos, esse ponto de vista leva a questão para o terreno da igualdade, cujo conceito depende de uma relação de simetria como consequência de uma condição original, na qual todos estão igualmente alinhados como pessoas livres e iguais. Como resultado desta análise, é possível salientar que o reconhecimento da liberdade e da igualdade das pessoas e da sua condição como sujeitos morais desempenha um papel fundamental na atribuição que cada um se dá como sujeito moral livre, e que considera o outro também como possuidor de igual capacidade.

Enquanto vinculada às escolhas dos indivíduos, a liberdade significa autonomia, isto é, eles se consideram - na condição de pessoas racionais e

${ }^{23}$ RAWLS, J. Justiça e democracia, op. cit, p. 31.

24 Idem, p. 100. 
razoáveis - como fontes apreciadoras das regras. "Na qualidade de pessoas livres, os cidadãos reivindicam o direito de que suas próprias pessoas sejam consideradas como independentes de qualquer concepção do bem específico ou de qualquer esquema específico de fins últimos, e de não ser identificados a alguma dessas concepções." 25

As pessoas também são autônomas porque são responsáveis por seus interesses e por seus objetivos, podendo revisar, controlar suas necessidades e desejos de acordo com uma determinada concepção de bem que elas esposam. Enfim, os cidadãos se consideram livres em três sentidos:

1. Pelo fato de se considerarem a si mesmos e aos demais como moralmente capazes de ter uma concepção do bem... 2. São livres na condição de fontes originárias (self-originating) de reivindicações legítimas [...] 3. Porque são capazes de assumir a responsabilidade dos seus fins, o que afeta a maneira de avaliar suas diversas reivindicações. ${ }^{26}$

Nessa medida, na compreensão da liberdade dos agentes nesses três sentidos, Rawls partilha do conceito de liberdade positiva, presente na ideia de autonomia. E isso vale tanto para a posição original (autonomia racional) como para a sociedade bem-ordenada, quando, então, a autonomia se completa. Apenas nessa sociedade que a liberdade se constitui de forma plena e real na condição de indivíduos que são cidadãos, membros desta sociedade, na qual eles abandonam o pressuposto da situação ficcional da pessoa representante na posição original.

Quando as partes, adotando os princípios de justiça, atuarem na sociedade segundo os justos termos da cooperação social, chega-se a uma concepção plena de autonomia das pessoas que realizam as faculdades do "racional” e do "razoável." A autonomia racional não deve ser confundida com a autonomia plena das pessoas. A primeira é um parâmetro para informar as escolhas dos representantes na posição original na medida em que são agentes de um processo de construção. ${ }^{27} \mathrm{~A}$ segunda constitui um ideal que se realiza no plano de uma sociedade bem-ordenada, quando a pessoa - o cidadão socialmente cooperativo dessa sociedade - exerce a

\footnotetext{
${ }^{25}$ RAWLS, J. Justiça como equidade. Uma reformulação, op. cit., p. 30.

${ }^{26}$ Idem, pp. 226/230.

${ }^{27}$ RAWLS, J. Justiça e democracia, op. cit., p. 54.
} 
autonomia plena amparada pelo elemento "razoável” do sentido de justiça. A diferença entre a autonomia completa e autonomia racional é a seguinte:

a autonomia racional só se efetiva a partir da nossa capacidade de ser racional e a partir da concepção determinada do bem que temos num dado momento. A autonomia completa abrange não apenas essa capacidade de ser racional, mas também a capacidade de fazer com que a nossa concepção do bem avance de maneira compatível com o respeito dos termos equitativos da cooperação social, a saber, os princípios de justiça. ${ }^{28}$

De qualquer modo, a liberdade é vista pelo lado de que é racional compreender escolhas que derivam exclusivamente da autonomia das pessoas, seja como parceiros na posição original, dando "prioridade à proteção das condições sociais que permitiram concretizar seus interesses superiores e à busca de bases para um acordo, malgrado as severas limitações da informação que o véu de ignorância implica;" 29 seja como cidadãos de uma sociedade bem-ordenada. Compreender a liberdade no sentido positivo significa definir a pessoa segundo uma concepção modelo que a descreve como agente moral livre e igual, e que possui a capacidade de ter um efetivo senso de justiça, de agir segundo princípios que definem os termos equitativos da cooperação social e de ter a capacidade para formar, revisar e seguir uma concepção do bem. Nesse sentido, a liberdade é representada como o poder das pessoas para formular reivindicações de maneira autônoma. E essa característica vale para a posição original e que terá, também, plena validade numa sociedade bem-ordenada. Tal perspectiva se coaduna com o conceito de liberdade positiva, próxima da concepção kantiana de autonomia.

De acordo com a teoria moral de Kant, a autonomia é concebida como o "princípio supremo da moralidade," uma vez que ela constitui a condição fundamental para que o indivíduo possa ser considerado autor de suas ações e alguém capaz de agir livremente, isto é, não está sujeito a outras leis senão àquelas que atribui a si mesmo, atestando a qualidade moral de alguém que sujeito que, nessa condição, possa a ser considerado como pessoa: ser respeitado como agente livre sem nenhum uso instrumental da sua identidade moral.

${ }^{28}$ Idem, p. 163.

29 Idem, p. 100. 
Uma pessoa é o sujeito cujas ações lhes são suscetíveis de imputação. A personalidade moral não é, portanto, outra coisa senão a liberdade de um ser racional sob leis morais (enquanto a personalidade psicológica é meramente a faculdade de ser consciente da sua identidade em diferentes estados da própria existência). Disto resulta que uma pessoa não está sujeita a outras leis senão àquelas que dá a si mesma (ou isoladamente ou, pelo menos, a si e com os outros ao mesmo tempo). ${ }^{30}$

Trata-se da ideia do respeito a todas as pessoas, considerando-as como um fim em si mesma e jamais como meio para se obter uma outra finalidade. E a pessoa é tratada como um fim em si mesma quando a sua vontade autônoma é considerada legisladora, pois não está submetida ao determinismo de forças heterônomas. Definida como "propriedade da vontade pela qual ela é para si mesma a sua lei (independente de toda constituição dos objetos do querer),"31 a autonomia da vontade é compatível com a obediência à lei, mas de uma lei criada pelo próprio sujeito. Como agente moral, ele constrói leis (racionais) segundo os critérios formais e normativos da razão prática que adota como máximas ou regras de conduta e, nesse processo, ele torna-se consciente do caráter vinculante da lei moral à sua ação.

Em razão do aspecto essencial da democracia na realização e asseguramento da pluralidade de valores, e contrário a qualquer tentativa de realização moral de uma teoria (política) da justiça, Rawls avalia criticamente o kantismo, com o objetivo de se livrar do universalismo ético promovido por uma teoria filosófica abrangente, qualquer que seja ela, inclusive a concepção da autonomia moral de Kant no contexto do seu idealismo. ${ }^{32}$ Pretende, assim, dar uma interpretação processual ao kantismo, afastando-se, desse modo, do idealismo transcendental, uma vez que a teoria da justiça como equidade não é uma "teoria kantiana no sentido estrito"33

\footnotetext{
30 KANT, I. Metaphysik der Sitten. (Rechtslehre) Band VIII In: Werke in 12 Bänden, Hrsg. von Wilhem Weischedel, Frankfurt am Main: Suhrkamp, 1993, p. 329, 330 (AB 22, 23).

${ }^{31} \mathrm{KANT}, \mathrm{I}$. Grundlegung zur Metaphysik der Sitten. Band VII, Werke in 12 Bänden, Hrsg. von Wilhelm Weischedel, Frankfurt am Main: Suhrkamp, 1991, p. 74 (BA 87).

$32 \mathrm{O}$ idealismo da ética kantiana tem por base os seguintes aspectos: a) uma validez normativa a priori (formal), e que se distingue das práticas das instituições políticas que poderiam, de outro modo, constituir uma alternativa histórica para a normatividade político-social das regras morais; b) uma racionalidade prática que legitima essa validade normativa, e que não poderia ter outro princípio de legitimação; c) um sujeito autônomo, suporte "noumênico" da normatividade e da razão prática.

${ }^{33}$ RAWLS, J. Justiça e democracia, op. cit p., 48.
} 
$\mathrm{O}$ adjetivo kantiano exprime apenas uma analogia, não uma identidade; ele indica que minha doutrina se parece em boa parte, com a de Kant, e isso se dá a respeito de muitos pontos fundamentais, pelo que está bem mais próximo dela do que de outras doutrinas morais tradicionais que nos servem como termos de comparação. ${ }^{34}$

A teoria da justiça como equidade difere do kantismo em pontos importantes. Em primeiro lugar, ela interpreta a moralidade ligada ao seu papel social, pois o objeto primeiro da justiça é a "estrutura básica da sociedade"; enquanto o imperativo categórico de Kant se aplica às máximas de indivíduos sinceros e conscienciosos em sua vida cotidiana.

A teoria da justiça como equidade procede no sentido inverso. Sua construção se inicia com um acordo coletivo unânime que rege a estrutura básica da sociedade, e a seguir todas as decisões dos indivíduos e das associações devem ser tomadas nesse contexto e em conformidade com esse acordo anterior ${ }^{35}$.

Em segundo lugar, no que diz respeito à concepção de pessoa e à sua autonomia moral, a diferença está no fato de que nós, como cidadãos de uma sociedade bem-ordenada, nos consideramos como sujeitos plenamente autônomos. Para Kant, tal reconhecimento é dado pelo "fato da razão", isto é, "pelo nosso reconhecimento de que a lei moral é a autoridade suprema para nós na medida em que somos seres razoáveis e racionais" 36 .

A ênfase na concepção política de pessoa na fase posterior do pensamento de Rawls, ao invés de ser uma retomada pura e simples do conceito kantiano da dignidade do ser humano, representou uma elaboração mais ampla da mesma, e constitui um pressuposto teórico importante da obra rawlsiana na linha do liberalismo político. Além dos elementos normativos, a concepção de pessoa retrata uma base histórica como o resultado de ideais implícitos ou latentes na cultura pública (política) das sociedades democráticas ${ }^{37}$.

\footnotetext{
34 Idem, p., 48.

35 Idem, p. 107.

36 Idem, p. 108.

${ }^{37} \mathrm{O}$ elemento kantiano da autonomia da pessoa deve ser nuançado na teoria rawlsiana. Aqui, também, o idealismo é corrigido por uma exigência de referência à realidade social. O filósofo procura evitar a forte perspectiva moral do kantismo, e insiste que a sua teoria deve ser vista na mudança de perspectiva ou de enfoque: de uma visão voltada para uma concepção moral de pessoa de inspiração kantiana, presente em Uma teoria da justiça, para uma perspectiva política mais visível nos escritos dos anos 90 , a partir do Liberalismo político. Ou seja, o abandono de um enquadramento moral da pessoa segundo uma doutrina moral abrangente (da individualidade e da autonomia presentes em S. Mill e em Kant), e
} 
A validade de uma concepção pública da justiça que seja aceitável para todos aqueles que se concebem como pessoas livres e iguais, capazes de agir de modo racional e razoável e de participar da cooperação social, não pode ser deduzida a partir de uma exigência puramente transcendental. O cidadão como pessoa livre e igual não é um ideal moral, mas um princípio que pertence à justiça (política) enquanto pressuposto para a sociabilidade dos cidadãos numa sociedade democrática e pluralista. Mas, nem por isso, a sua validade normativa não resulta de uma mera configuração temporal que $\mathrm{o}$ historicismo apresenta como verdade. A ênfase na concepção política da pessoa deve, também, afastar uma interpretação antropológica, social ou psicológica de uma possível natureza humana.

Enquanto concepção política, a teoria da justiça "deve tentar apoiar-se apenas nas ideias intuitivas que estão na base das instituições políticas de um regime democrático constitucional e nas tradições públicas que regem a sua interpretação. Trata-se de uma concepção política em parte porque ela provém de uma certa tradição política" ${ }^{38}$. Partindo das intuições fundamentais da tradição cultural das sociedades democráticas, como as ideias de liberdade e de igualdade, a teoria da justiça pretende evitar não só o idealismo do formalismo universalista como o historicismo relativista na tentativa de construir uma concepção política apoiada nas ideias intuitivas que estão presentes nas tradições públicas dos regimes democráticos.

A caracterização dos bens primários não se reduz a fatos históricos ou sociais. "Mesmo que a determinação dos bens primários invoque um conhecimento das circunstâncias e necessidades gerais da vida social, ela só é possível à luz de uma concepção da pessoa dada previamente"39. Eles devem ser construídos a partir de um pressuposto formal (normativo) que a concepção de pessoa contém em si mesma, mas que a tradição liberal das sociedades democráticas modernas erigiu como ideal mediante práticas políticas, jurídicas e morais que estas sociedades foram, pouco a pouco, consolidando. Assim, a formulação de uma concepção pertinente de liberdade e de igualdade, deve estar

que sugere vínculos com uma ideia do bem, em prol de uma análise norteada pela concepção de razão pública, na trilha dos esclarecimentos dos escritos posteriores.

${ }^{38}$ RAWLS, J. Justiça e democracia, op. cit , p. 205.

39 Idem, p. 166. 
enraizada nas noções mais fundamentais de nossa vida política e que esteja de acordo com a nossa concepção de pessoa [...] A teoria da justiça como equidade tenta descobrir as ideias fundamentais (latentes no bom senso) relativas à liberdade, à igualdade, à cooperação social e à pessoa formulando o que eu chamarei de concepções modelos. ${ }^{40}$

O método de Rawls, definido como um procedimento que busca um "equilíbrio reflexivo", revela-se como o espelhamento normativo da sociedade liberal moderna, no sentido de construir e sistematizar as convicções básicas dessa sociedade, mediante um consenso por justaposição (overlapping consensus). ${ }^{41}$ Esse procedimento manifesta-se na elaboração das concepções modelos como se fossem ideias "reguladoras" extraídas da realidade social e histórica das sociedades liberais modernas como forma de evitar o relativismo histórico e o ceticismo conceitual.

Olhamos - comenta Rawls a propósito do seu método do abstracionismo concreto - para as ideias fundamentais implícitas na cultura política pública e procuramos descobrir como é que os próprios cidadãos podem, após a reflexão devida, querer conceber a sua sociedade como um sistema equitativo de cooperação ao longo do tempo. Nesse contexto, é essencial formular concepções idealizadas da sociedade e da pessoa, portanto, necessariamente abstratas, associadas àquelas ideias fundamentais, para encontrar uma concepção política razoável da justiça."42

Mas por que a liberdade é fundamental? Se a questão básica é estabelecer princípios de justiça que possam regular a sociedade, pelo menos na sua estrutura básica, segundo critérios equitativos que sejam razoáveis para todos e adequados para a vida social, Rawls propõe uma teoria que procura satisfazer essas condições. Esses princípios, contudo, não podem ser impostos

\footnotetext{
${ }^{40}$ Idem, p. 52,53.

${ }^{41}$ A ideia de um equilíbrio ponderado (reflective equilibrium) retrata um ponto de vista que não é estabelecido segundo critérios fundacionais que buscam princípios indubitáveis, mas pelo procedimento construtivista que estabelece a explicitação de perspectivas que, embora divergentes, podem chegar a um consenso sobre o ideal moral de uma pessoa e de uma sociedade bem-ordenada. Esses ideais são atribuídos a criaturas fictícias, mas que nos representam, ou melhor, espelham os nossos ideais como 0 resultado de um consenso. O nosso ponto de vista, como resultado de um reflective equilibrium, tem por objetivo discutir e decidir se a concepção modelo de pessoa (e, também, a de sociedade bem-ordenada e a formulação dos dois princípios) corresponde às nossas ideias, incorporadas na nossa cultura (moral e política) pública, após uma devida reflexão. O que se pretende é submeter as várias concepções morais a uma mais ampla avaliação filosófica argumentativa segundo um atento exame teórico.

${ }^{42}$ RAWLS, J. Liberalismo político, op., cit., p. 69.
} 
ou decididos à revelia dos sujeitos que vão se submeter a eles. Há necessidade do consentimento dos sujeitos envolvidos, o que pressupõe a autonomia - no sentido da liberdade positiva - para a livre escolha desses princípios. E se eles podem escolher, o resultado dessa escolha deve ser o mais racional possível, desde que os indivíduos não estejam submetidos a influências heterônomas nas suas escolhas.

Enfim, o que explica essa concessão ao significado positivo de liberdade, aderente à concepção de autonomia da pessoa? Não seria suficiente permanecer, por questão de clareza terminológica e de estratégia conceitual, dentro dos limites da concepção de liberdade negativa como um valor jurídico institucional, precavendo-se, assim, das implicações "ideológicas" que a concepção de liberdade positiva pode suscitar na suspeita já aduzida por Berlin?

Uma resposta possível a essas indagações consiste em dizer que o pressuposto normativo deve estar presente por considerar a autonomia como um atributo essencial da pessoa, pois, sem a escolha dos princípios de justiça a cooperação social tornar-se-ia extremamente frágil, uma vez que não está amparada pelo reconhecimento mútuo de pessoas livres (autônomas) e iguais, e que desejam cooperar como membros de uma sociedade bem-ordenada. E isso é uma exigência que deve ser igualmente conferida a todos. Tal constatação leva a discussão para o terreno da igualdade, cujo conceito vincula-se ao de liberdade.

Dado que nos colocamos na tradição do pensamento democrático, devemos também considerar os cidadãos como pessoas livres e iguais. A ideia intuitiva básica, aqui, é a de que, em virtude das suas capacidades morais, assim como das da razão, do pensamento e do julgamento que a ela estão ligadas, dizemos que essas pessoas são livres. Ademais, dado que elas possuem essas capacidades na medida necessária para serem membros integrais da sociedade, dizemos que são iguais entre si. ${ }^{43}$

Se a liberdade se restringir à concepção negativa de liberdade, a igualdade tornar-se-ia moralmente irrelevante enquanto qualidade essencial da pessoa, constituindo apenas um valor jurídico. Mas, se as pessoas são iguais como quer a teoria rawlsiana - é preciso admitir a autonomia delas na perspectiva moral/normativa, aderente ao conceito de liberdade positiva, como um atributo que pertence às pessoas. Isso significa dizer que elas "são

${ }^{43}$ Idem, p. 216. 
fontes autônomas de reivindicações no sentido de que têm um valor próprio, que não deriva de deveres ou de obrigações anteriores em relação à sociedade ou a outras pessoas, nem é determinado por seu papel social específico." ${ }^{4}$ Essa característica da pessoa deve ser atribuída igualmente a todos.

A igualdade é importante porque ela vai permitir uma equalização formal de todos na posição original, e que todos serão tratados de forma similar numa relação de simetria de indivíduos que têm as mesmas propriedades essenciais definidoras da categoria moral da pessoa: a liberdade, as duas faculdades morais e a capacidade de cooperação. Assim, se os parceiros são colocados numa posição de igualdade é porque possuem os "mesmos direitos e os mesmos poderes no procedimento que permite concluir um acordo" 45 no uso de suas autonomias. Tanto a igualdade como a liberdade constituem, assim, elementos essenciais na caracterização das partes na posição original, e estão presentes antes mesmo do acordo na elaboração dos princípios que serão adotados pelos representantes racionais.

Se os cidadãos estão representados segundo uma equitativa igualdade na situação original, todos receberão igual proteção dos princípios de justiça. Com efeito, a expressão "justiça como equidade" diz respeito a princípios extraídos de um acordo realizado numa situação inicial (posição original) de igualdade, ela mesma considerada justa.

A equidade das circunstâncias nas quais o acordo é atingido se transfere para os princípios de justiça escolhidos. Dado que a posição original situa as pessoas livres e iguais de maneira equitativa umas em relação às outras, a concepção de justiça, seja ela qual for que elas adotarão, será igualmente equitativa. ${ }^{46}$

A igualdade desempenha, portanto, um papel fundamental na representação dos cidadãos na posição original, pois é nessa situação de igualdade que as pessoas morais e livres são representadas. Ela está presente no conteúdo dos princípios de justiça por duas vias: primeiro, porque tais princípios foram escolhidos sob condições justas de igualdade; e, segundo, ela se explicita em regras institucionais que vão garantir a igualdade de oportunidades e corrigir distorções, como aquelas que resultam das

\footnotetext{
44 Idem, p. 93.

${ }^{45}$ RAWLS, J. Justiça e democracia, op. cit., p. 103.

${ }^{46}$ Idem, p 57.
} 
desigualdades econômicas e sociais, nos termos em que prescreve o segundo princípio de justiça. ${ }^{47}$

Numa sociedade democrática bem-ordenada, os cidadãos se consideram mutuamente como pessoas morais iguais, na medida em que cada um é de igual modo capaz de compreender e de aplicar uma concepção pública da justiça. Eles podem, dessa forma, ser tratados como iguais em todos os aspectos nas questões de justiça política, isso porque pessoas morais têm direito a uma justiça igual. São, também, iguais porque podem tomar parte da cooperação social, respeitando os termos apropriados dessa cooperação.

Por conseguinte, todos são capazes de respeitar os princípios de justiça e de ser membros integrais da cooperação social ao longo de sua vida. Com base nisso e no fato de que cada indivíduo é uma fonte autônoma de reivindicações legítimas, todos se consideram como igualmente dignos de ser representados em qualquer procedimento destinado a determinar os princípios de justiça que devem reger as instituições básicas de sua sociedade. Essa ideia de dignidade igual está alicerçada na capacidade igual (que suponho concretizada) de compreender e de aplicar a concepção pública da cooperação social. 48

\footnotetext{
${ }^{47} \mathrm{~A}$ definição de igualdade concebida por Rawls como um atributo correlato à liberdade foi analisada por alguns autores como R. Dworkin, que considera a igualdade como um valor mais fundamental que a liberdade. Diferente desta, que é um produto do contrato, o direito à igualdade é imanente aos homens e à personalidade moral a eles imanente e que, assim, são conduzidos por princípios de justiça: "O direito ao respeito mútuo não é [...] um produto do contrato, mas uma condição para a admissão na posição original. Este direito é 'devido aos seres humanos enquanto pessoas morais'[...] É desfrutado por todos homens que podem ser justos e não apenas pelos homens que podem participar do contrato. Por isso, este é um direito que não emerge do contrato, mas é assumido no procedimento contratual, como sendo um direito fundamental." (DWORKIN, R. The original position. In: DANIELS, N. Reading Rawls, Stanford, California: 1989, p. 51). Apesar da liberdade e a igualdade serem elementos constitutivos e indissociáveis da personalidade moral, Dworkin acaba separando esses dois elementos e concede prioridade à igualdade na formulação e na execução de uma teoria da justiça, o que não ocorre com 0 procedimentalismo de Rawls. Na definição de igualdade, Dworkin ressalta que todas as pessoas têm direito à igual consideração e ao igual respeito. Esse direito pode ser considerado mediante dois direitos distintos: 0 direito de igual tratamento (equal treatment), isto é, de ser tratado como igual e refere-se à prerrogativa de uma pessoa "à mesma distribuição de bens e oportunidades que qualquer outra pessoa possua ou receba;" e o direito em ser tratado como igual (treatment as an equal), ou seja, o direito a igual consideração e respeito na decisão política sobre como bens e oportunidades serão distribuídos. Liberdade e igualdade são elementos constitutivos e indissociáveis da personalidade moral. Contudo, Dworkin considera a segunda mais fundamental que a primeira, pois, diferente da justificativa da prioridade léxica dos princípios de justiça, o direito à igualdade e 0 respeito mútuo possibilitam a realização das liberdades básicas, e não o caminho inverso.

${ }^{48}$ RAWLS, J. Justiça e democracia, op. cit., p. 97.
} 
A liberdade é um atributo, uma qualidade da pessoa que se define como autônoma. Mas é uma característica normativa intrínseca à pessoa do ponto de vista dos elementos essenciais da concepção modelo de pessoa. Já a igualdade não pode ser deduzida da mesma forma. Ela só é um atributo se outras pessoas forem também livres, e cuja validade normativa é deduzida mediante procedimentos de comparação que operam o reconhecimento recíproco de pessoas como agentes livres. Impõe-se aqui a interferência do elemento mediador do reconhecimento.

Os membros de uma sociedade bem-ordenada são pessoas no sentido de que, a partir do momento em que atingem a idade da razão, todos possuem e reconhecem nos demais um senso de justiça, bem como uma compreensão do que é uma compreensão do seu bem. Os cidadãos são iguais na medida em que se consideram uns aos outros como detentores de um direito igual de terminar e de avaliar de maneira ponderada os princípios primeiros de justiça que devem reger a estrutura básica da sua sociedade. ${ }^{49}$

Se o ponto de partida é a consideração das pessoas capazes de serem membros cooperativos da sociedade, e que respeitam os termos equitativos da cooperação, então as legítimas restrições às liberdades individuais não são meramente de ordem jurídica segundo o princípio do impedimento legal da liberdade negativa, mas têm uma razão moral de caráter normativo para a sua validade: elas representam uma garantia à cooperação social baseada no respeito mútuo de pessoas iguais e livres que desejam cooperar como membros de uma sociedade bem-ordenada, e o fazem apenas no reconhecimento moral deste princípio.

Ou seja, as pessoas são livres, na medida em que elas se reconhecem mutuamente como seres morais que têm a capacidade de adotar uma concepção do bem, porque todos são vistos como iguais na medida em que eles têm as faculdades morais necessárias para a cooperação social e participação no empreendimento societário como cidadãos iguais. A liberdade das pessoas depende, portanto, de uma relação de igualdade entre elas, mas que é aferida pelo reconhecimento de suas liberdades como pessoas. $\mathrm{O}$ reconhecimento desempenha, assim, um papel fundamental no processo de atribuição da igualdade, na medida em que cada um reivindica para si mesmo a condição ou a capacidade de sujeito moral livre e, de igual modo, o faz para os outros no reconhecimento de que todos, como pessoas, possuem

49 Idem, p. 55. 
igual capacidade. Mas, para que essa igualdade possa adquirir o estatuto de um pressuposto normativo, ela deve surgir como o resultado de uma condição original em que todos estão simetricamente alinhados como pessoas livres e iguais. Já como cidadãos de uma sociedade bem-ordenada eles também se reconhecem como pessoas morais iguais e livres. São iguais porque cada um tem um igual respeito e consideração; e se consideram livres não só porque eles se consideram como "fontes autônomas de reivindicações fundamentais", mas também porque eles "se reconhecem mutuamente como moralmente capazes de ter uma concepção do bem [...] e que são considerados como capazes de revisar e modificar essa concepção sobre bases razoáveis e racionais" 50 .

Apesar da relativa importância da categoria do reconhecimento demonstrada pela presença de elementos intersubjetivos como o respeito mútuo exercido pelas pessoas e o desejo de cooperação que elas manifestam, bem como pela consideração recíproca das pessoas como seres livres e autônomos - ainda assim, o aspecto da intersubjetividade é meramente descritivo e coadjuvante na teoria rawlsiana, sobretudo, no que diz respeito à possibilidade de uma abordagem intersubjetiva que a igualdade e a liberdade poderiam suscitar, a partir da categoria filosófica do reconhecimento. A rigor, a própria noção de liberdade deveria ser definida em termos de uma teoria da intersubjetividade, pela qual a dinâmica do reconhecimento adquire papel constituidor da liberdade para além do seu caráter normativo meramente auto-referente.

$\mathrm{Na}$ medida em que a liberdade faz parte da concepção modelo de pessoa, a autonomia inerente a essa concepção é dos agentes - parceiros na posição original e cidadão na sociedade bem-ordenada -, e se constitui em instrumento volitivo para a livre escolha dos princípios de justiça, objeto do contrato social. E a igualdade como corolário da definição de pessoa quanto à extensão dos seus atributos que são reconhecidos como válidos para todos, participa desta mesma concepção. Apesar do método construtivista do reflective equilibrium ter um peso especial na teoria rawlsiana, não só para evitar uma interpretação da posição original como um procedimento de escolha, racional e neutro, como também para entender a condição ideal da pessoa numa perspectiva dialógica e não monadológica - afinal, a concepção idealmente construída do conceito de pessoa é definida e decidida por "nós",

\footnotetext{
50 Idem, p. 93, 94.
} 
segundo um debate público esclarecido - a consideração do elemento intersubjetivo na teoria de Rawls, sobretudo, na sua concepção de pessoa e dos atributos da liberdade e da igualdade, é, ainda, bastante pálida ${ }^{51}$.

O princípio moral de que as pessoas são "fonte autônomas de reivindicações fundamentais," agentes que têm independência em relação aos seus fins, contempla a ideia de autonomia e se insere na concepção de liberdade no sentido positivo, representada pela "capacidade de formular reivindicações de maneira autônoma." 52 Além de ser um valor institucional no contexto jurídico da liberdade negativa, a liberdade é concebida segundo o ideal da concepção modelo de pessoa autônoma na "posição original" e do cidadão no ideal de sociedade bem-ordenada.

Se o ponto de partida é a consideração das pessoas capazes de serem membros cooperativos da sociedade e que respeitam os termos equitativos da cooperação, então, o sentido da liberdade deveria limitar-se ao aspecto meramente legal, na ótica da liberdade negativa. Ainda que essa assertiva seja procedente, a liberdade revela, também, um fundo normativo representado pelo ideal da autonomia tanto da pessoa na concepção modelo como do cidadão. Assim, se a liberdade deve valer para todos, ela adquire o estatuto teórico da autonomia que o conceito de liberdade negativa quer evitar como forma de se proteger das externalidades conceituais que desviam o sentido objetivo da liberdade como ausência de impedimentos. Mas, uma vez que os princípios de justiça são pactuados, a liberdade representada pelo primeiro princípio assume o papel prioritário na acepção de liberdade negativa, subsistindo com a autonomia plena do cidadão de uma sociedade bemordenada.

${ }^{51}$ Baynes adverte que, apesar da referência à lista dos bens sociais primários - e que, portanto, a autonomia da pessoa representada não suprime os aspectos sociais e históricos -, a descrição rawlsiana dos dois poderes fundamentais da pessoa (a capacidade para formar, revisar e perseguir uma concepção do bem e a capacidade para ter um efetivo senso de justiça) "ainda não captura adequadamente a dimensão intersubjetiva da autonomia moral. O que é mais importante, a representação de Rawls do ponto de vista moral na posição original parece, claramente, minimizar a importância do reconhecimento intersubjetivo das normas para a sua validade. As partes na posição original não discutem os seus interesses ou as normas sociais que as modela; antes, a posição original (como descrição do ponto de vista moral) é construída de tal forma que os princípios de justiça são escolhidos de acordo com a regra (monadológica) da escolha maximin sob condições de incerteza." (BAYNES, K. The normative ground of social criticism. Kant, Rawls and Habermas. New York: State University of New York Press, 1992, p. 4)

${ }^{52}$ RAWLS, J. Justiça e democracia, op. cit., p. 100. 
Aparentemente dicotômicas, como sugere a análise de Berlin, essas duas formas de liberdade são compatíveis, tornando auspiciosa a elaboração de uma teoria unificada da liberdade no pensamento rawlsiano. A solução conciliatória que resulta da análise rawlsiana em compreender a liberdade segundo uma perspectiva de integração das concepções de liberdade consiste, portanto, em recorrer tanto ao método das concepções modelos do ideal normativo, como à referência histórica da realidade social, na qual este modelo está implicitamente se revelando como verdade cultural e política. Enfim, a sua teoria da justiça

tenta estabelecer uma concepção idealizada de certas ideias intuitivas, fundamentais, como as da pessoa como ser livre e igual, de uma sociedade bem ordenada e do papel público de uma concepção da justiça política, e que ela vincula essas ideias à ideia ainda mais fundamental e geral da sociedade como sistema equitativo de cooperação através do tempo, de uma geração à seguinte. Os direitos, os deveres e os fins são apenas elementos desse tipo de concepção idealizada. Assim, a teoria da justiça como equidade está de fato baseada em concepções ou, como Elisabeth Anderson me sugeriu, em ideais, já que essas ideias intuitivas fundamentais refletem ideais implícitos ou latentes na cultura pública de uma sociedade democrática. Nesse contexto, a posição original é um procedimento de apresentação que fornece um modelo da força não do direito natural com uma preocupação e um respeito iguais, mas sim dos elementos essenciais dessas ideias intuitivas fundamentais que precisam os argumentos em favor dos princípios de justiça que aceitamos após reflexão. ${ }^{53}$

A perspectiva de Rawls no Liberalismo político, ao orientar-se pela aceitação dos valores culturais, sociais e políticos das modernas sociedades liberais democráticas, particularmente o fato histórico dos direitos e liberdades individuais, bem como uma concepção pública de justiça, denotou uma sensibilidade histórica de aceitação dessa sociedade ${ }^{54}$. Essa perspectiva

\footnotetext{
53 Idem, p 220, 221.

${ }^{54}$ É possível detectar o interesse de Rawls pela densidade conceitual da tese hegeliana da reconciliação da racionalidade do mundo com a realidade da vida social e política dos homens em um dado momento histórico. Não há dúvida de que as diferenças entre o liberalismo político de Rawls e o idealismo político
} 
conciliatória se revela, também, na tentativa do autor em formular uma teoria que possa ser a expressão a mais razoável possível de uma conciliação entre a tradição liberal de ênfase à liberdade (Locke, S. Mill) e a tradição do igualitarismo democrático (Rousseau, Marx), voltada prioritariamente para a igualdade. Se um dos objetivos de Uma teoria da justiça consiste em propor uma análise dos direitos e das liberdades básicas e atestar a sua prioridade em princípios de justiça, o outro objetivo procurou superar a unilateralidade dessa análise por uma concepção da igualdade, o que conduz ao elemento da justa igualdade das chances e ao princípio da diferença. Essa segunda perspectiva, orienta-se, assim, pelo igualitarismo da tradição democrática.

Não há dúvida de que o pensamento de Rawls operou com estes dois componentes tradicionais da filosofia política: o compromisso à liberdade individual — na versão da liberdade negativa corporificada no valor liberal de sustentação das liberdades civis - e a crença na igualdade que se vincula ao princípio da autonomia da pessoa, na perspectiva da liberdade positiva, igualmente compartilhada por todos; o que resulta na exigência de uma distribuição mais igualitária dos recursos de que dispõe uma sociedade. Contudo, a presença desses dois componentes revelou uma tensão entre a ênfase à liberdade individual, presente na prioridade que Rawls atribui ao primeiro dos seus princípios, e as exigências distributivistas e igualitaristas da sociedade, presentes no segundo princípio, e cujo apelo é para a fraternidade. Tensão que o liberalismo político de Rawls pretendeu resolver reconciliando liberdade negativa com positiva e, ambas, com igualdade. Procura, assim, se afastar da perspectiva do atomismo formalista abstrato que a crítica comunitarista atribui à sua teoria..$^{55}$

de Hegel são imensas. Contudo, ambos revelam preocupação em elaborar um diagnóstico da realidade, e concordam com a tese de esta realidade pode ser reconciliada com a medida da sua racionalidade, seja pelo lado da idealidade do conceito para Hegel, seja pela perspectiva das concepções modelos para Rawls. Para ambos, "a estratégia da reconciliação significa tornar compatível a racionalidade dos ideais com a efetiva razoabilidade das ações humanas, e que a dimensão normativa que a racionalidade dos ideais representa na vida social não é estranha ao mundo real dessas ações." (RAMOS, C. A. Hegel, Rawls e o tema da reconciliação. In: Veritas, v. 52, n. 1, 2007, p. 41.)

55 A engenhosa concepção política de pessoa que Rawls constrói dá lugar a inúmeros problemas apontados pelos seus críticos, particularmente, os chamados comunitaristas, dentre eles, Alasdair MacIntyre After virtue (1981), Michael Sandel. Liberalism and the limits of justice (1982), M. Walzer. Spheres of justice: Defense of pluralism and equality (1983), C. Taylor. Philosophy and the human sciences: philosophical papers (1985) e Sources of the Self (1990), J. Raz. The morality of freedom (1986). Uma das dificuldades que estes críticos apontam reside na separação do ser humano em dois níveis de realização: um abstrato (formal, fictício, racional, individual) e outro real (material, pessoa plena, social), sendo o primeiro pensado como princípio racional, independentemente do segundo que, 
De qualquer modo, o liberalismo político de Rawls não se restringe à concepção negativa de liberdade da tradição liberal. Tudo indica que ele opera, de início, com a concepção de liberdade positiva (autonomia) presente na concepção modelo de pessoa, e avança para uma concepção negativa, quando especifica uma lista de liberdades básicas com base na realidade social e histórica da tradição das sociedades democráticas. Contudo, o resultado de uma possível teoria unificada da liberdade limita-se à mera justaposição dos dois aspectos da liberdade, ainda que necessários e articulados no seu modo de manifestação - como bem jurídico primário e como faculdade de escolha da pessoa.

Com efeito, a liberdade nos seus dois modos de referência conceitual - a autonomia da concepção positiva como fonte de reivindicações independentes das pessoas e a sua inserção como bem primário da concepção negativa em uma sociedade bem ordenada - retrata, na verdade, duas formas de sua manifestação que coexistem de modo unificado. Mas, esses dois lados da liberdade demonstram, ainda, a predominância do estatuto autorreferente da liberdade, seja como um bem primário ou direito subjetivo, seja como autonomia da pessoa.

A rigor, não há no liberalismo político de Rawls uma proposta explícita de uma teoria unificada da liberdade - mesmo porque não é essa a intenção do autor - que pudesse demonstrar de forma imanente e consistente a articulação recíproca das duas faces da liberdade. Essa perspectiva tornar-seia plausível se a liberdade fosse analisada como fenômeno subjetivo e social que se constitui mediante relações intersubjetivas, presentes nas relações humanas de mútuo reconhecimento vinculadas à igualdade. Nessa linha de investigação, o fato subjetivo da autonomia e o seu reconhecimento em um outro sujeito, igualmente autônomo, adquire consistência objetiva, uma vez

embora real, é determinado por mecanismos abstratos de representação na escolha dos princípios básicos na posição original para a constituição e organização de uma sociedade justa. Sandel, por exemplo, vê no "eu" rawlsiano um "sujeito desencarnado" (disembodied subject). C. Taylor, tendo em vista a defesa do multiculturalismo e das particularidades sociais de uma democracia social liberal, defende a tese de que as ideias liberais devem ter um enraizamento nos valores comunitários, pressupondo uma compreensão compartilhada destes valores numa comunidade. Sem abandonar 0 princípio liberal dos direitos e das liberdades individuais, mas rejeitando o individualismo metodológico e o normativismo abstrato de um determinado tipo de liberalismo, Taylor propõe uma análise da pessoa a partir de uma rede social de interlocução linguística, onde o sentido do bem, do próprio eu e dos outros homens estão numa íntima correlação. Taylor reatualiza a prioridade da Sittlichkeit hegeliana sobre a Moralität kantiana, assumindo uma análise histórica na constituição dos sujeitos e das instituições sociais e políticas. 
que a liberdade representa um valor social (público, político) de um bem subjetivo - a autonomia. Somente assim ela torna-se um direito fundamental, suscitando a criação de mecanismos jurídicos de proteção contra interferências indevidas.

\section{REFERÊNCIAS BIBLIOGRÁFICAS}

BERLIN, I. Dois conceitos de liberdade. In: HARDY, H. et al. (ed.) A Busca do ideal. Uma antologia de ensaios. Trad. Teresa Curvelo, Lisboa: Editorial Bizâncio, 1998.

BAYNES, K. The normative ground of social criticism. Kant, Rawls and Habermas. New York: State University of New York Press, 1992.

DANIELS, N. (ed.). Critical studies on Rawls'A Theory of Justice. Stanford Stanford Univ. Press, 1989.

DWORKIN, R. The original position. In: DANIELS, N. Reading Rawls, Stanford, California: 1989.

KANT, I. Grundlegung zur Metaphysik der Sitten. Band VII, Werke in 12 Bänden, Hrsg. von Wilhelm Weischedel, Frankfurt am Main: Suhrkamp, 1991.

Metaphysik der Sitten. Rechtslehre. Band VIII, Werke in 12 Bänden, Hrsg. von Wilhem Weischedel, Frankfurt am Main: Suhrkamp, 1993.

MACCALLUM, G. Jr. Negative and positive freedom. In: MILLER. C. (ed.) Liberty. New York: Oxford University Press, 1991, p. 102.

MACINTYRE, A. After virtue : a study in moral theory. London : Duckworth, 1981.

MILLER, D. (ed.). Liberty. Oxford : Oxford Univ. Press, 1991.

RAWLS, J. Uma teoria da justiça. Trad. Almiro Pisetta e Lenita M.R. Esteves. São Paulo: Martins Fontes, 1997. . Théorie de la justice. trad. C. Audard. Paris: Seuil, 1987. . Justiça e democracia. Trad. Irene Paternot, São Paulo: Martins Fontes, 2000. 
. Lectures on the history of moral philosophy, Cambridge: Harvard University Press, 2000. 1996. . Liberalismo político. Trad. João S. Nunes, Lisboa: Editorial Presença,

. Collected papers. Edited by Samuel Freeman, Cambridge: Harvard University Press, 2001.

- Justiça como equidade. Uma reformulação. Trad. Cláudia Berliner, São Paulo: Martins Fontes, 2003.

RAMOS, C. A. A fundamentação política da ideia de pessoa e de sociedade no liberalismo de J. Rawls e a crítica comunitarista. In: OLIVEIRA, N.F. (org.) Justiça e política. Homenagem a Otfried Höffe, Porto Alegre: Edipucrs, 2003.

. Hegel, Rawls e o tema da reconciliação. In: Veritas, v. 52, n. 1, 2007.

RAZ, J. The morality of freedom. Oxford : Clarendon Press, 1986.

SANDEL, M. Liberalism and the limits of justice. Cambridge: Cambridge University Press, 1982.

TAYLOR, C. Multiculturalism. Princeton : Princeton University Press, 1994.

As fontes do Self. A construção da identidade moderna. Trad. Adail U. Sobral e Dinah de Abreu Azevedo, São Paulo: Loyola, 1997. . La Liberté des modernes. Paris: PUF, 1997.

WALZER, M. Las esferas de la justicia : una defesa del pluralismo y la igualdad. Trad. H. Rubio, México: Fondo de Cultura Económica, 1983. 